\title{
El Killer. Representaciones inestables de un homicida
}

Felipe Oliver Fuentes y Rogelio Castro Rocha Universidad de Guanajuato

Resumen:

El Killer, de Josué Montijo narra los asesinatos en serie de Juan Benito Aybar, un ciudadano "común” que súbitamente comienza a liquidar a los drogadictos de San Juan de Puerto Rico. Pero lejos de ofrecer una visión unilateral del asesino que permita descifrarlo como un psicópata tradicional, la novela entrega un conjunto de versiones contradictorias que imposibilitan cualquier intento de clasificación. En el proceso, lo siniestro irrumpe en la novela pues el lector descubre que el asesino es el último defensor del "orden convencional" en una sociedad en franca descomposición.

Palabras clave: Literatura puertorriqueña, novela posmoderna, representaciones inestables, "carne monstruosa”, lo siniestro. 


\section{Abstract:}

El Killer by Josué Montijo describes the serial murders of Juan Benito Aybar, a "common" citizen who suddenly starts killing the drug addicts of San Juan. But far beyond of offering a unilateral vision of the assassin as the prototype of the "traditional psychopath", the novel offers a set of contradictory versions making imposible any attempt of classification. In the process a sinister turn out for justice emerge as the assassin becomes a sort of defender of the "right order".

Keywords: Puerto Rican literature, Postmodern novel, unstable portrait, "the savage anomaly", "the unheimlich".

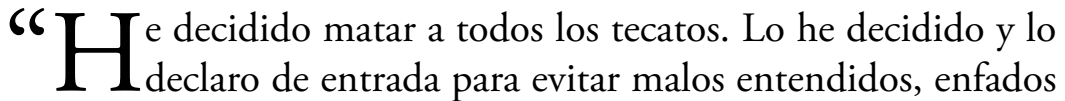
o reclamos futuros" (Montijo, 2010: 7). Con estas palabras inicia la novela El killer (2007), de Josué Montijo. El argumento, simple por lo demás, se revela de una vez y para siempre en las líneas recién trascritas; Juan Benito Aybar, un ciudadano "común y corriente" de San Juan de Puerto Rico súbitamente decide comenzar a asesinar a los adictos que pululan en la capital puertorriqueńa. Los motivos detrás de su accionar son, al menos en apariencia, también muy simples:

Solicito un esfuerzo de quien lee estas líneas para que entienda que, desde luego, no estoy poseso ni nada por el estilo. Lo hago por una necesidad imperiosa. Me siento sofocado, aborrecido $y$ cansado de tanto verlos en la calle con sus caras de muertos, de mártires requemados por el sol, con sus brazos cundidos de llagas, el olor desagradable, los andrajos y ese insaciable apetito intravenoso que los hace pedir dinero donde quiera (8).

La identidad del asesino y sus móviles son revelados al lector desde la primera página de la novela. Lo que no quiere decir que la intri- 
ga y el misterio hayan sido desterradas de la obra. Al contrario, si algo distingue a la novela es la ambigüedad en torno al personaje y lo tremendamente elusiva que resulta su conducta cuando intentamos explicarla dentro de su contexto social. En las próximas páginas exploraremos en el proceso mismo de construcción del texto para describir cómo el propio asesino edifica una imagen elusiva de sí mismo que, además, entra en contradicción con las psicopatías "habituales" desde las cuales terceros pretenden encasillarlo. El resultado final es un texto rizomático que se rehúsa a ser clasificado a partir de afirmaciones o proposiciones superiores que organicen un sentido unívoco e inamovible.

El Killer se compone por un total de tres segmentos narrativos. El primero de ellos supone el diario del homicida, una especie de bitácora en donde Juan Benito registró sus crímenes. Páginas después, el texto ofrece un perfil sobre el asesino elaborado por un periodista especializado en crímenes a quien el propio Juan Benito habría contactado para remitirle su diario. Finalmente, la novela cierra con una carta redactada por el asesino en donde ofrece una versión sobre sí mismo cuyas afirmaciones hasta cierto punto difieren con el diario. Dichos segmentos serán analizados en su momento. Partiendo por el diario, es necesario señalar desde ahora que éste no pretende ser un retrato fiel de la vida privada de su autor o una relación detallada, científica y objetiva de los crímenes. Se trata de "un texto en bruto" (8) en donde el autor parece más preocupado por enmascarar su yo que en desnudarlo a través de la intimidad y la cotidianidad. Al respecto, las siguientes líneas son muy sugestivas:

Renuncié a la posibilidad de mirar los periódicos, noticieros y demás. No quiero consumir ni creerme un cuento de mí. Mi cuento me lo hago yo y altero las líneas cuando quiero. No deseo ver una alteridad de mi persona descrita bajo los esquemas ni consignas de otro. No me importa. No quiero promoción, ni condena, ni 
siquiera simpatía velada. Quiero esto como un algo íntimo, por lo menos hasta ahora que lo comparto con ustedes (30).

Basta esta entrada para instalar de manera definitiva las dudas sobre lo narrado. Si ya de por sí es difícil no poner en entredicho la frabilidad de un asesino, — cómo creer en las palabras de quien todas luces padece algún tipo de trastorno-, ¿qué decir de un asesino que además reclama el derecho explícito de alterar las líneas a placer para crear su propio cuento? Sin embargo, no es la "cordura" de Juan Benito Aybar o la libertad reclamada para modificar a placer lo narrado el elemento que mejor potencia la incertidumbre sobre la "veracidad de la verdad". Después de todo, el lector contemporáneo ha sido acostumbrado a dudar a priori de las narraciones, sobre todo aquellas que se expresan en primera persona. La inestabilidad del relato de El Killer responde esencialmente a la decisión de no confrontar su yo con la alteridad de los "esquemas y consignas de otro". Si la (re)construcción de la personalidad supone un vértigo originado por el choque entre la opinión que posee el sujeto sobre sí mismo (descripciones personales) en concierto $\mathrm{u}$ oposición con la opinión que sobre él guardan los demás (descripciones sociales), el diario del asesino construye una identidad fracturada e incompleta. Dicho con otras palabras, una vez anulada la dimensión social, emerge un yo volátil y poco sustancial pues no existe un contrapunto que dote de un mínimo de "espesor" a la subjetividad retratada en el diario.

Durante la primera parte de la novela el lector transita entonces por las páginas del diario de Juan Benito sin saber la repercusión de sus actos ni mucho menos el impacto mediático y policial de los mismos. Algunos indicios permiten suponer que los homicidios no han pasado desapercibidos; por ejemplo, en uno de sus vagabundeos en busca de una nueva víctima advierte una menor presencia de tecatos en las calles del barrio y con un dejo de orgullo se atribuye el fenómeno. Sin embargo, al mantenerse fuera 
de los reportes policiales y de las especulaciones y conjeturas que arrojan los medios de comunicación para mantener su "yo" puro e incontaminado, el diario no permite deslindar la realidad de lo narrado. Al no existir el contrapunto de la prensa que confirme o contradiga aquello que el asesino afirma, el lector no es capaz de decidir si el yo que emerge en las páginas del diario es "real" o por el contrario se trata de una construcción parcial o totalmente ficticia. Por consiguiente, no sabemos si nos enfrentamos al relato de un psicótico que se "crea un cuento", o al retrato pormenorizado y "realista" de un psicópata.

La bibliografía especializada sobre las marcas o síntomas ineludibles que respectivamente definen al psicótico y al psicópata es enorme. Sin el afán de agotar la discusión ni mucho menos de entregar un análisis completo que nos alejaría de nuestro objetivo, preferimos resumir el lúcido y clásico ensayo de Normal Mailer The White Negro, Superficial Reflections on the Hipster (1957). De acuerdo con Mailer, el psicótico es un individuo enfermo que no guarda contacto alguno con la realidad, y cuyo pensamiento es por naturaleza caótico y desorganizado. Por lo general, sufren de alucinaciones y son incapaces de vivir en sociedad pues su comportamiento les impide interactuar. Por el contrario, el psicópata se distingue por su especial lucidez y extraordinaria capacidad para seducir o incluso manipular a sus semejantes. Si acaso prefieren enajenarse de la esfera social, no responde a una incapacidad per se para interactuar sino a una rebelión consciente fundamentada a partir de ciertos prejuicios personales. Por último, el psicópata es incapaz de sentir empatía o culpa, siendo entonces proclive al crimen por diversas razones: su inteligencia y meticulosidad le permite elaborar minuciosos planes para burlar los operativos policiales, al tiempo que su incapacidad afectiva anula la posibilidad de identificarse con la víctima o sentir remordimiento. Por decirlo de algún modo, el "psicópata modelo" responde al patrón del ase- 
sino serial narcisista y megalómano tantas veces representado en el cine estadounidense.

Tomando en cuenta lo anterior, ya desde la primera entrada del diario, Juan Benito esboza una serie de afirmaciones que de antemano anulan o desarticulan cualquier pretensión de encuadrar al personaje dentro de las patologías más comunes. "No soy ningún enviado de Dios, ni oigo voces (salvo las que cantan en mis audífonos)" (7). Basta esta simple declaración para descartar que se trate de un psicótico. De hecho, si algo podemos afirmar con plena certeza sobre el personaje es su perspicacia para construir un relato, aunque fragmentario y no siempre verídico, claro y congruente. Que se trate de un psicópata es acaso más probable, pero el hecho de que El Killer admita la ausencia de "un plan mayor" siendo entonces su obra "más artesanal" y "flexible" (9), pone en entredicho el dictamen. Además, siempre juzgando desde la poca, falsa o tergiversada información que otorga el asesino en su diario, no le interesa jugar al gato y al ratón con la policía ni tampoco alimentar un ego narcisista desde el espejo que le ofrece la prensa. Y por último, El Killer termina por experimentar culpa y remordimientos por sus acciones hasta llegar al suicidio, lo que jamás ocurriría con un psicópata pues son incapaces de experimentar dichos sentimientos.

Desde luego, no existe nada más peligroso y falso que tratar de explicar la conducta de un personaje ficticio desde los postulados epistemológicos de la psicología. Y al hablar de ficción lo que está en juego no es el hecho de que Juan Benito no forma parte del mundo empírico o real, dato obvio por lo demás, sino el carácter mismo de su diario que explícitamente reclama el derecho de alterar los datos a placer. Por consiguiente, la narración debe ser entendida como un deliberado propósito por desmantelar desde la ficción la concepción de lo racional, como una crítica a las categorías establecidas para explicar cómo o por qué un individuo se 
convierte en asesino serial; o bien, porque su mente se ve "invadida" por voces que lo impelen a cumplir un deber superior (psicótico), o bien como un impulso narcisista por acaparar mediante el horror la atención de la sociedad para exhibir su superioridad intelectual (psicópata). Una vez que Juan Benito se autolibera de las motivaciones epistemológicas que pecando de reduccionismo tratan de fijar la conducta límite de los homicidas, emerge un personaje ficticio capaz de desestabilizar cualquier representación psicosocial convencional. ¿Cómo explicar entonces los asesinatos? ¿Cómo o por qué un estudiante universitario "común y corriente" se convierte en un asesino serial? ¿Y por qué en Puerto Rico? Estas preguntas son las mismas que atormentan a Josué Montijo.

El segundo segmento narrativo de la novela responde a las reflexiones de un periodista y criminólogo llamado Josué Montijo (alter ego del autor), a quien el asesino habría enviado su diario antes de suicidarse. Montijo se esfuerza por insertar y entender el material como el efecto o resultado de un algo inteligible. Es decir, se esfuerza por esclarecer los móviles que impulsaron a Juan B., por explicar los asesinatos desde bases más sólidas que el simple hartazgo de éste frente la horda de adictos vagabundeando en las calles. Así, en primer término Montijo ensaya una pequeña biografía sobre el personaje, al que primero define como "un niño muy tranquilo pero no tímido" con un "sentido del humor sobresaliente pero que no rayaba en el típico bufón de los grupos infantiles" (119), y más adelante como un adolescente con inclinaciones artísticas y de "ánimo sobrio, aunque no antisocial ni altanero" (120). En resumen, nada que desde las representaciones convencionales sobre los homicidas permita leer en su infancia los primeros indicios de una futura conducta tan deplorable. Su ambiente familiar, de igual modo, se antoja lo suficientemente sano como para deslindar de ante mano la menor responsabilidad. Ni la biografía ni el estudio del entorno inmediato explican nada de manera 
convincente pues carece de las señales univocas que evidencien una psicopatología, y en su pasado no existen hechos traumáticos que sugieran la ulterior formación de una conducta degenerativa.

Líneas después, Montijo procede a invalidar las razones que el propio asesino postula como el motor de sus acciones; ¡es realmente posible aceptar que alguien ejecute a mansalva a más de una decena de personas sólo por cansancio? Sobre este punto volveremos más adelante. Por último, el periodista culpa a la sociedad en su conjunto a través de la teoría del blowback atribuida Darrell Y. Hamamoto, especialista en criminología en general y en los asesinos seriales en particular. Bajo esta óptica el asesino no sería otra cosa que "el efecto boomerang de una conducta violenta respondida con otra más violenta" (123). En ese sentido, el periodista otorga un valor central a la referencia de Max Payne, el popular videojuego cuyo título utiliza Juan Benito para nombrar a su empresa aduciendo la simplísima razón de que "me gusta el nombre y ya” (10). Pero no nos engańemos, advierte Montijo, el videojuego supone una "clave inicial de lo que se proponía" pues "quienes hayan cotejado este juego, sabrán lo cruel y salvaje que es" (124). Las preguntas que al respecto se desprenden son tan obvias que formularlas casi parece innecesario: ¿pero por qué Juan Benito? Si todos vivimos en ciudades violentas y estamos expuestos a los mismos videojuegos, películas o programas de televisión, ¿por qué sólo unos cuantos son susceptibles a devolver con mayor fuerza la hostilidad recibida? El periodista se ve obligado entonces a imputar al autor de los asesinatos una de las patologías que al parecer Juan Benito, con toda intención evadió al autorrepresentarse desde la ficción:

Me parece que internamente, aunque no lo confiesa abiertamente de este modo, le dedicaba muchísimo tiempo en planificar sus ataques y elaborar estrategias cada vez más sofisticadas; para mí, que fui espectador de todo el operativo que se originó para lograr su captura, no había forma de burlar toda la vigilancia y el patru- 
llaje de forma silenciosa. Estábamos frente a un delincuente astuto, altamente organizado y conocedor de los límites de la policía. Estas y otras características han hecho de Juan B., un ejemplo del asesino en serie más o menos estándar dentro de las consideraciones de los expertos (124).

Es necesario desmentir a Juan B., presentarlo como un asesino estándar para normalizarlo en su anomalía, pues de otra manera estaremos obligados a reconocer que aquello incómoda; lo único que distingue y separa al homicida del resto es que él sí se atrevió a llevar a cabo lo que en secreto todos siempre han deseado. Desde este punto de vista, el horror o simple rechazo que puede eventualmente producir en el lector las descripciones de los asesinatos no responde a la violencia per se, sino a la siniestra irrupción freudiana de un deseo que por convención social estamos obligados a reprimir. De no destergiversar las tergiversaciones del criminal es casi inevitable aceptar y reconocer que la "carne monstruosa" debe ser eliminada. Por consiguiente, lejos de condenar a Juan B., celebramos sus acciones pues nosotros también hemos deseado matar a quienes interfieren con el orden público.

Al hablar de "carne monstruosa" recuperamos las observaciones que Michael Hardt y Antonio Negri postulan en su conocido trabajo Multitud (2005). De acuerdo con los autores, ante la cada vez más evidente agonía de una sociedad unívoca y homogénea, "tradicional y feliz", el espacio social contemporáneo ya no puede ser representado como un cuerpo orgánico uniforme. Por consiguiente, el término carne, ambiguo y amorfo, emerge como el más apropiado para representar una multitud configurada por micro colectividades dispares - las minorías étnicas y sexuales, los inmigrantes, las tribus urbanas, los tecatos...-, que se rehúsan a ser atrapadas "en la jerarquía orgánica de un cuerpo político" (Hardt, 2004: 228). Imagen no exenta de polémica, pues por su aparente ingobernabilidad: 
Para muchos, esas multitudes que no son pueblos ni naciones, ni siquiera comunidades, representan un ejemplo más de la inseguridad y el caos, que han traído consigo el colapso del orden social moderno. Son catástrofes sociales de la posmodernidad que se asemejan, según esa óptica, a las horribles criaturas generadas por los errores de la ingeniería genética, o a las terroríficas consecuencias de los desastres industriales, nucleares o ecológicos (Hardt, 2004: 228).

Si el flâneur de finales del siglo XIX y principios del XX miraba con horror y fascinación los nuevos actores sociales que parió la modernidad, el personaje de Montijo asesina con más fastidio que desprecio a los actores que defeca la posmodernidad. Pues para él los adictos no son más que cuerpos de desecho, "oxidados, molidos, con los brazos picados y arratonados por las fauces de la infección [...] piernas destrozadas, supurando líquidos amarillos, con boquetes que si te fijas bien miras hace el hueso [...] los signos más elocuentes del abismo de la carne [...] monstruos entre monstruos" (85). Mientras Hardt y Negri sueñan con la utópica integración total de la multitud a partir de lo común, en una carne unida en su heterogeneidad y como tal llena del potencial necesario para reorientar la sociedad, el asesino recorre la dirección contraria al enfocar su atención en la cara menos amable de la multitud. ¿Acaso el adicto puede ser re-integrado al proyecto social? ¿Podemos objetivamente esperar alguna actividad o servicio de su cuerpo? ¿Por qué entonces no habríamos de eliminarlo? Y aquí ya no estamos hablando únicamente de los adictos; Juan B. admite en su diario haber comenzado a asesinar a los tecatos tal como pudo haber comenzado con cualquier otro colectivo cancerígeno; los desempleados que desangran al estado solicitando todo tipo de fondos y pensiones, los vagabundos ordinarios, los inmigrantes dominicanos "quienes han hecho todo lo posible por ordenar todo 
un cagadero" (101), y hasta los motociclistas que violan las leyes de tránsito, por dar algunos casos. Desde luego, el asesinato no resuelve ni mucho menos enfermedades sociales como la drogadicción, el estado proteccionista y parasitario, la pobreza o la inmigración, pero al menos combate los síntomas más evidentes. Sin pretenderlo, o incluso saberlo, Juan B. se convierte en el último bastión del orden convencional, aquel cuya disolución celebran Hardt y Negri, salvo por un ligero matiz: el asesino no es un utopista y su empresa no aspira a erradicar de manera definitiva los problemas de San Juan.

Hablando de San Juan, la novela, aunque ambientada en la capital de la isla, ofrece diversos pasajes en los que el narrador compara la violencia y la miseria de Puerto Rico con la que la literatura, el cine y la televisión atribuyen sin muchos fundamentos a Colombia, Brasil o Cuba. No es entonces descabellado afirmar que San Juan de algún modo pierde su condición de periferia para reclamar un lugar central desde el cual representar a América Latina. Dicho con otras palabras, si en la novela la figura del tecato representa a todos colectivos emergentes desechables, a la carne monstruosa que amenaza con destruir el orden convencional, San Juan a su vez simboliza a todo el subcontienente latinoamericano, acaso la única región del globo que experimenta todos los males de la posmodernidad sin haber gozado antes de los beneficios de la modernidad. A diferencia de los defensores de McOndo para quienes en el fluido intercambio de imágenes a través del mass media, la movilidad de los cuerpos, la emergencia de nuevos actores sociales y el logo norteamericano son las señales que anuncian la exitosa inserción de Latinoamérica en la escena contemporánea, el autor implícito de El Killer mira con desconfianza lo que podemos calificar de neoliberalismo sin expansión económica, alienación y violencia sin riqueza material, y "civismo bondadoso" (Montijo, 2010: 13) en lugar de asistencia social. 
El segundo segmento narrativo de la novela consiste entonces en un fracasado esfuerzo por socializar a Juan B., por condenar su comportamiento desde los parámetros morales aceptados ( $\mathrm{O}$ impuestos?) y por explicar su conducta desde el instrumental de la ciencia. Pero se trata de una representación fracasada pues en el plano personal no logra descubrir esas causas primeras que empujaron a Juan B. al asesinato sistemático. Al abrir el análisis a la dimensión social cita teorías ajenas a las que respalda con la violencia de los videojuegos a falta de mejores argumentos, y al final se esmera por encerrar al personaje dentro de los límites del asesino serial estándar. Al respecto de esto último, los argumentos que ofrece pueden ser rebatidos con cierta facilidad. Por ejemplo, el periodista asegura que la policía montó un operativo completo y meticuloso para aprehenderlo, siendo entonces el fracaso de las pesquisas la prueba irrefutable de la inteligencia superior propia del psicópata. Sin embargo, podemos recorrer la dirección contraria y afirmar que si algo prueba la victoria del homicida es la incompetencia de la policía y la apatía e incapacidad del gobierno a la hora de proteger a los desvalidos. Nada que sorprenda al lector latinoamericano promedio. $Y$ en última instancia, si acaso el asesino no miente al afirmar en varias oportunidades su firme obstinación de mantenerse al margen de cualquier dato que revelara las acciones de la policía, su éxito sería ante todo el resultado del azar. ¿No es acaso lógico suponer que al improvisar antes que planear, burlaba con mayor eficiencia los cálculos de un cuerpo de seguridad cuyo éxito dependía de la detección y anticipación de un patrón inexistente?

La lectura que Josué Montijo propone del diario de Juan B.,es sospechosa. Como periodista vinculado al departamento de policía está obligado a asumir una postura en concierto con la Razón de Estado. De ahí que ratifique el interés y profesionalismo que las fuerzas oficiales concedieron al caso. De ahí que reconozca que "nuestra so- 
ciedad se enfrenta a una ola de actos violentos sin precedentes" (122) pero anteponiendo un "criterio ético y moral" (121) que impide justificar las acciones del homicida. Así, aunque no niega la posibilidad de que Juan B. sea el efecto de un espacio nacional en crisis, prefiere presentarlo como un caso excepcional, el primer asesino serial de Puerto Rico, para desplazar a un segundo plano problemas de mayor envergadura e imposible resolución. Es necesario que Juan B. sea el único monstruo de Puerto Rico para que la carne monstruosa recupere algo de humanidad desde del martirio. Pero como bien señala el propio asesino, "nadie tiene el monopolio de la aberración" (85).

La novela finaliza con la carta que Juan B. habría entregado a Josué Montijo junto con el manuscrito de su diario. A falta de un mejor adjetivo, el tercer y último segmento narrativo es lo que podríamos calificar como la confesión del asesino. La estructura del discurso confesional irrumpe a través de ciertas figuras retóricas. En primer término, mucho más que un simple destinatario, Montijo es impelido a desempeñar el rol del confesor, elemento clave pues a decir de Michel Foucault la confesión es imposible "sin la presencia al menos virtual de otro que no es simplemente el interlocutor sino la instancia que requiere la confesión, la impone, la aprecia e interviene para juzgar, castigar, perdonar, consolar, reconciliar" (Foucault, 1998: 78). El que el periodista no logre interpretar en su justa dimensión la confesión no inválida el carácter del discurso. Asimismo, la confesión por naturaleza es un relato retrospectivo, una mirada hacia atrás que pretende remover con celo las propias acciones. Pero no en un sentido crítico pues el objetivo final no consiste en formular un relato "histórico" o biográfico convencional, esto es elocuente, lineal y ordenado, sino como un testimonio caótico que remueve nuevos lugares escondidos con celo dentro del yo. Dicho de otra manera, el propósito del ejercicio retrospectivo no es el de descifrar objetivamente el pasado, sino el de descubrir desde la subjetividad las "causas ocultas" que 
finalmente condujeron al individuo a actuar de tal o cual manera. Usando las propias palabras de Juan B. de plantear el discurso en otros términos éste "hubiese perdido su valor fundamental como pieza de confesión sobre un yo que se fue relatando en segmentos, con mucha candidez y desnudez" (131). Sin embargo, y he aquí una nueva estrategia consciente para evadir cualquier clasificación fácil, el elemento principal del discurso confesional brilla por su ausencia: la culpa. El sacramento de la confesión reclama el arrepentimiento como condición insoslayable. Al respecto sólo tenemos un párrafo enigmático:

¿Por qué develar estas páginas? Por el silencio: linda forma de evadir el pronunciamiento del malestar. La confesión, la maquinaria que produce verdad no me encaja bien. Pero como siempre sucede, uno tiene que tranzar con aquello que a sabiendas no nos sienta de lo mejor. El silencio me pudría por dentro. En su contundente resonancia he padecido la urgencia de quebrarlo, por envidia, por incomodidad y de ese quiebre nace esto (129).

¿Qué quiere decir "quebrar el silencio" en este contexto? ¿La necesidad de liberarse de la contrición mediante la palabra, o el simple ego narcisista del psicópata que reclama la necesidad de ser reconocido? Como fue mencionado líneas arriba, la simple admisión de la culpa rompe la clasificación convencional del psicópata, por lo que estaríamos obligados a revisar el caso desde nuevas bases. A saber, que lo que separa a Juan B. del resto no es una psicopatía; apenas un simple criterio ético con el que es posible tranzar. Palabra clave, pues al enfrentarse con la maquinaria que produce la verdad el homicida no habla de sacrificio sino de negociación. ¿Pero qué es lo que se está negociando? ¿La resignación para enfrentarse desnudo con la verdad y reconocer la real existencia de la culpa? ¿O la licencia para confesar arrepentimientos falsos o parciales? En el primer escenario, la existencia de la culpa garantiza la verdad. En 
el segundo, la confesión se convierte en un juego más del asesino. La ambigüedad del pasaje expone al sujeto al mismo tiempo que lo enmascara. Quien logre descifrar este párrafo logrará también descifrar al asesino.

Recapitulando, la novela construye entonces tres versiones incompletas, a veces contradictorias y siempre dudosas sobre un mismo individuo. Pero lejos de ofrecer la posibilidad de construir una imagen única y más o menos completa reagrupando los fragmentos, de manera inevitable el personaje tiende a la dispersión. La inestabilidad de la representación no es ni mucho menos el mero resultado del contenido o si se prefiere del fondo. En el nivel de la expresión los diferentes discursos que en conjunto integrar al texto construyen también un relato fracturado e inestable. El primer segmento narrativo se autodefine como "formato de diario" sin "una cronología exacta” (10). Contradicción evidente que obliga Juan B. a reconocer líneas después "no sé si la naturaleza de mis escritos se ajusta a la definición de ese género" (10). El segundo segmento supone una editorial periodística destinada a disipar las dudas sobre lo narrado en el diario, pero los resabios ideológicos del periodista terminar por enturbiar aún más el retrato del criminal. Por último, el relato termina con una carta del asesino en donde extiende una confesión sin remordimiento explicito, un mea culpa sin culpa.

El contenido, la expresión y, por supuesto, el personaje sólo pueden ser entendidos como representaciones provisionales siempre abiertas a la articulación de un nuevo sentido. Incluso si pensamos la novela desde una posible vinculación con el género negro o el neopolicial latinoamericano a partir de la obvia presencia de ciertos elementos como el asesino, el espacio social en crisis y las víctimas, emerge en paralelo la ausencia de otros rasgos no menos vitales como la investigación, el detective y aquello que Juan B. define como "un plan mayor" que desemboque "en la solución final" (9). Lo anterior 
no es casual, conocida es la relación ineludible entre género literario y sociedad. Escribir implica tomar cierta postura que complazca los intereses de específicos de una élite cultural o simplemente al mercado. Acaso Montijo con toda intención escogió el texto fragmentario e incompleto, la anulación de la trama, la irreductibilidad del personaje para oponerse a un mercado que impone a los textos un conjunto de códigos, formatos y estilos preestablecidos. Así, a través de un cuerpo textual magullado, herido y grotesco que hace coincidir con plena conciencia el contenido y la expresión, lo poético y lo poetizado, el autor construye un cuerpo literario propio y personal que no complace sino al lector exigente. No perdamos de vista a Josué Montijo, dará de qué hablar.

\section{Bibliografía.}

Foucault, Michel, 1998, "Scientia sexuales", en Historia de la sexualidad 1, Voluntad de saber, Ulises Guiñazú (trad.). Siglo XXI, México, pp.65 -93 .

Fuguet, Alberto y Sergio Gómez, 1996, "Presentación del país McOndo", en McOndo. Antología de nueva literatura hispanoamericana, Gijalbo-Mondadori, Barcelona, pp.10-27.

Franco, Jean, 2003, "Cuerpos dolientes: narrativas de globalización”, en Decadencia y caida de la ciudad letrada, Debate, Madrid, pp. $287-$ 304.

Hamamoto, Darrell Y., 2002, "Empire of Death. Militarized Society and the Rise of Serial Killing and Mass Murder" en New Political Science, No 24, Issue 1, pp.105-120.

Hardt, Michael y Antonio Negri Hardt, 2004, "De Corpore", en Multitud, Juan Antonio Bravo (trad.), Debate, Buenos Aires, pp.188-265. 
Mailer, Norman, 1957, The White Negro, Superficial Reflections on the Hipster, San Francisco, City Lights Books, reeditado por Dissent magazine, 2010-10-25: http://www.dissentmagazine.org/issue/?issue=178 Montijo, Josué, 2010, El Killer, La secta de los perros, Río de las Piedras, Puerto Rico. 